\title{
Barriers to and facilitators of female Deans' career advancement in higher education: an exploratory study in Vietnam
}

\author{
Thi Lan Huong Nguyen
}

LH Martin Institute for Higher Education Leadership \& Management

170 Bouverie Street, Carton, VIC, 3053, Australia.

\author{
Hanoi University of Industry \\ Km 13, Minh Khai, Tu Liem, \\ Hanoi, Vietnam
}

Mobile phone: 0424525699

Email: nguyent1@student.unimelb.edu.au/lanhuonghic@yahoo.com

\begin{abstract}
Although the slow progress of female academics compared to their male colleagues and the challenges that female academic leaders have to face in taking leadership roles have been welldocumented, very little is known about female academic leaders and managers' career advancement in developing countries like Vietnam. This paper reports on an exploratory study of a research project funded by the Cambridge - Viet Nam Women Leadership Programme, which aims to advance an understanding of the status of, and identify strategies to empower, female academic managers in Vietnamese higher education. The focus of this paper is on university leaders and female Deans' perceptions of the barriers to female academic Deanship and female Deans' reflections on the facilitators for their career advancement. The study found that the main barriers are strong family obligations, negative gender stereotypes regarding females as leaders, and female academics' unwillingness to take management positions. The major facilitators of female Deans' career advancement are self-effort, strong family support, and, what is perceived to be, a favourable or 'lucky' selection context. The paper provides empirical evidence to support the view that family support is a crucial factor for female academic career advancement in Vietnam. Women are both an agent and an object of change in empowering female academic leadership.
\end{abstract}

Keywords

middle level management, female academic managers, women empowerment, Vietnamese higher education

\section{Introduction}

The fact that women are under-represented in leadership and management positions, including those in higher education, is well documented in the literature (Bornstein, 2008; Doherty \& Manfredi, 2006; Mai, 2007; McNeill, 2007; Va'zquez-Cupeiro \& Elston, 2006; Valian, 1998; Winchester, Lorenzo, 
Browning, \& Chesterman, 2006). There also is a large volume of literature that identifies the challenges and facilitators for women assuming leadership and management roles, in society generally and in academic institutions. However, there is little documentation of the experiences of female academic leaders' and managers' career advancement in south-east Asian contexts, particularly in Vietnam.

This article aims to fill this information gap by examining the experiences of female Deans in selected Vietnamese universities. The Deanship role is chosen because of its centrality to higher education middle management (Meek, Goedegebuure, Santiago, \& Carvalho, 2010). The article will identify both the barriers and facilitators these female Deans have experienced in pursuing their careers. The study is based on findings from a research project funded by the Cambridge - Viet Nam Women Leadership Programme, which seeks to advance an understanding of the status of, and identify strategies to empower, female academic managers ${ }^{1}$ in Vietnamese higher education.

This research is significant for at least two reasons. Firstly, it helps to fill a gap in the literature on female academic leadership. The literature has been dominated by a number of studies on women in higher education management in Western settings, particularly in the UK, USA, and Australia and in some developing countries such as China, Malaysia, Turkey, etc. However, very little has been written on the subject in Vietnam. Secondly, understanding the barriers and facilitators for women in assuming leadership positions in higher education is important in deepening and broadening understanding of leadership development as a whole within higher education (Madsen, 2010). The task of empowering female leadership is essential not only in terms of achieving gender equity but also for organizational productivity and human capital development (Bell, 2009; Cheung \& Halpern, 2010).

Following a review of the relevant literature, the context and methods of the study are presented. Then the main findings of the study are reported and discussed. Finally, conclusions and recommendations arising from the study are presented.

\section{Conceptual framework}

In the absence of an appropriate theoretical framework grounded in the Vietnamese experience, a very general socio-structural framework is employed based on the literature of women in management and leadership positions, focusing on the higher education contexts. The framework is used as a guide to analyse the barriers and facilitators for female Deans' career advancement in Vietnam. Two main components of this framework are barriers to and facilitators for women assuming leadership and management positions.

\footnotetext{
${ }^{1}$ In this paper, the term 'managers' is deliberately used to refer to Deans and 'leaders' refers to university's most senior leadership positions such as Rectors or Vice Rectors, because in Vietnam Deans enjoy a low level of autonomy and in classifying between university leaders and lower level of leaders, they are only considered as department leaders, not university leaders.
} 


\section{Barriers to women taking leadership and management positions}

Researchers both outside and inside academia agree broadly that for women who aspire to top leadership positions, paths exist but are full of 'twists and turns', both unexpected and expected (Eagly \& Carli, 2007, p. 64). Researchers put forward a range of theories to explain the under-representation of women in senior management positions. However, the two most common are based on psychological and cultural theories. From a psychological perspective, negative gender stereotypes regarding female leaders may critically impede women's leadership advancement (Eagly \& Carli, 2007; Heilman, 2001; Schein, 2001). From a cultural perspective, women have to face multiple cultural barriers in accepting leadership positions arising from the 'macro' socio-political level, the 'mesco' ${ }^{2}$ organizational level, and the 'micro' individual level (Cubillo \& Brown, 2003).

\section{Psychological barrier: think manager-think male attitudes}

Prejudicial attitudes towards women as leaders is arguably the most ingrained barrier to women in leadership and management (Twombly, 1998). Women are often thought to be more communal: affectionate, helpful, friendly, kind, and sympathetic, interpersonally sensitive, gentle, and soft-spoken. These communal characteristics often are considered to be inappropriate for effective leadership and management. In contrast, men are considered to be more agentic: aggressive, ambitious, dominant, self-confident, forceful, self-reliant, and individualistic. These agentic traits are often associated with successful management (Eagly \& Carli, 2007; Eagly \& Johannesen-Schmidt, 2001). These stereotypes impede women's career advancement as it is assumed that women do not have the attributes associated with management. Such views about men and women are often implicitly acquired and thus very resistant to change.

Research indicates that the 'think manager-think male' attitude is an entrenched view, especially among males (Schein, 1973, 2001). This phenomenon translates equally well into the university sector as "think professor - think male" (Tharenou, 1994) and "think vice chancellor - think male" (Tilbrook, 1998). Such attitudes not only limit women's access to leadership roles but also create biased evaluations for women when they occupy such roles (Bailyn, 2003; Eagly \& Carli, 2007; Heilman, 2001; Mabokela, 2003). If women choose to be highly communal, they can be criticized for lacking agentic qualities; in contrast, if they are too agentic, they may be criticized for lacking empathy. Whichever way they act, they may be considered to lack the 'right stuff' for powerful jobs (Eagly \& Carli, 2007). Due to this paradox between the way women and managers are supposed to behave, women leaders may find it very difficult to successfully fulfill leadership and management roles - damned if you do, damned if you don't. However, it should be acknowledged that there are obviously women who are successful leaders and managers.

\footnotetext{
2 'mesco' is a term used by Cubilllo and Brown (2003) to denote a middle level between the macro and micro level.
} 


\section{Cultural barrier 1: the "macro" socio-political level}

Socio-political barriers refer to entrenched hegemonic cultural traditions of a region or country that women are generally required to follow (Cubillo \& Brown, 2003). These cultural expectations often put women in a disadvantaged position compared to men in trying to advance their careers (Cubillo \& Brown, 2003; Oplatka, 2006).

Research has shown that women, particularly those in traditional societies, are expected to take more family responsibilities than men, such as solely careering for their children, husband, and extended family. They are also required to do more domestic work. Such role expectations have been found to be an important obstacle in academic career progression for women in Turkey (Neale \& Ozkanli, 2010), Thailand, Hong Kong, Singapore, and Malaysia (Luke, 2000), Kenya (Olser, 1997, cited in Oplatka, 2006), and even for Asian American Pacific Islanders (Chen \& Hune, 2011) and African American women (Blackwood \& Brown-Welty, 2011). The pressure of family responsibilities results in women continuing to be the ones who interrupt their careers, take more days off work, and work part-time. As a result, they have fewer years of job experience, and fewer hours of employment per year, which slow their career progress and reduces their earnings. Even women who have found a way to reduce family pressures by sharing housework and child rearing with husbands, relatives, or paid workers are still perceived as having domestic responsibilities which will be inappropriate for promotion, especially to time consuming, demanding positions (Eagly \& Carli, 2007). With the bulk of domestic work still falling on their shoulders, women's career advancement continues to be slowed.

Apart from family responsibilities, women are also required to follow particular cultural traditions imposed by the society in which they live (Cubillo \& Brown, 2003; Luke, 2000; Oplatka, 2006; Twombly, 1998). For example, in a study on how women's career paths and opportunities are shaped by the intersection of cultural values and structures, and legal systems of the state in four countries in South East Asia, Luke (2000) found that Asian values or Asian culture promotes a specific concept of femininity. The stereotype ideal of women's roles is as dutiful wives, mothers, and homemakers (Stivens, 1998a, b, cited in Luke, 2000). Women's public conduct should be 'subdued', 'quiet', and 'withdrawn'. As a result, women have to perform an 'Asian sense of what it means to be womanly' or else 'you will lose face' (Luke, 2000). Being required to be confined within cultural rules of feminine propriety, women are more reluctant to demonstrate their leadership skills in public or to socialize with colleagues to build professional networks. This limits professional opportunities and advancement.

\section{Cultural barrier 2: the 'mesco' organizational level}

Beside socio-political culture barriers, the highly masculinist culture at universities can act as another barrier for women interested in leadership and management positions (Chen \& Hune, 2011; Tilbrook, 1998; White, 2003.). Like most large institutions, universities were historically the realm of a certain class of men, so university practices and norms are constructed around men's life experiences (Meyerson, 2000). Because these practices are well-established they are taken for granted and very difficult to change (Bailyn, 2003). Although 
women have entered the workforce and have added enormous value, the balance of power within organisations still is in favour of men. Consequently, female academics are often disadvantaged in pay and promotion.

The literature provides evidence on how organizational structures, norms, and values disadvantage women in their career advancement. For example, the culture of long hours makes it difficult for women who have family commitments (Airini et al., 2011); poor policies on women returnees from leave; and discrimination against women in selection and promotion through the syndrome of supporting 'people like us' (Mann, 1995). While research is highly valued for academic promotion, women are required to do more teaching and pastoral care than their male colleagues on similar appointment levels (Spurling, 1997, cited in Tilbrook, 1998, White, 2007). In an established university in the United Kingdom, the human resources department informally looked for interested candidates before an election of a Head of Department. Because women were less likely to get involved in the informal networking required to get noticed, the initial informal search was considered lacking in transparency and possibly a form of indirect discrimination (Doherty \& Manfredi, 2006). In Malaysia and Hong Kong, training specifically for women managers is often not a university priority (Luke, 2000). Or if a general management training program is provided, it does not fit well with women's schedules. In short, policies and processes in higher education can act as barriers against women assuming leadership and management positions.

\section{Cultural barrier 3: the 'micro' individual level'}

As a consequence of the imposition of traditional male hegemony at the sociopolitical and organizational level, women's internalisation of barriers may also contribute to their under representation in management. Some examples of these barriers are lack of competitiveness, lack of confidence, and a fear of failure (Cubillo \& Brown, 2003).

With the pressure of dutiful compliance with societal "norms", values and roles, women may feel that they need to adhere to the social expectations of their roles. As a result, women are reluctant to 'come forward and parade their achievements in annual competitions for promotion or professorial conferment' (Doherty \& Manfredi, 2006, p. 568). Luke (2000) argues that they may have even internalized a sense of 'gender neutral meritocratic idealism'. Organizational structures that bias power in favour of men also make women unenthusiastic to engage in "politicking and power-mongering" and a general "distaste for political party" (Arroba and James, 1987, cited in Mann, 1995). In eschewing the role of power and politics, some have argued that women demonstrate a lack of political competence, which can impede career progress.

\section{Facilitators for women in higher education leadership and management}

Whilst research focuses on the underrepresentation of women in management and barriers to success, it may be argued that insufficient original research has been undertaken on facilitators for women gaining senior academic leadership and management positions in higher education (Airini, et al., 2011; Chen \& Hune, 2011). A literature review of this topic has found very few relevant publications in English (Airini, et al., 2011; Blackwood \& Brown-Welty, 2011; Cubillo \& 
Brown, 2003; Harris, Wright, \& Msengi, 2011; Turner, 2007; Twombly, 1998). From this scant literature, the three most common facilitators appear to be personal factors, family support and mentor support.

\section{Personal factors}

Senior academic women seem to demonstrate very strong personalities such as being self-motivated, independent and hardworking. In interviews with 18 women in positions of academic leadership at the University of Costa Rica, Twombly (1998) found that to rise to the top of their professions these women were determined not to be left behind by trying their best to survive many battles through their own excellence, tenacity, and political skill. They also worked twice as hard as their male colleagues to succeed. In a study of narratives drawn from women aspiring to leadership and management in nine different educational contexts, from very different parts of the world, Cubillie and Brown (2003) similarly found that although they had to face hostile male-dominated cultures, these women appeared to be extremely independent, confident and self-motivated. In studying pathways to leadership for women of color in California Community Colleges, Blackwood \& Brown-Welty (2011) also found that these women always tried to be the best in their position. Working hard and working smart were also the strategies employed by a number of other female leaders and managers (Cheung \& Halpern, 2010).

\section{Family support}

Support from family is the second common facilitator for women's career advancement. By reviewing the literature, Cheung \& Halpern (2010) reported that women leaders in various studies all mentioned the importance of family support in achieving their top positions. While the extended family provided great help with housework and childcare, the husbands could also take on a substantial share of household chores or take the role of the trailing spouse, i.e. being willing to move to a new location with uncertain career prospects for the advancement of their wife's career. Family and partner support were also recognized as playing an important role in three 'first' Mexican American, Native American, and Asian Pacific/Asian American women university presidents' (Turner, 2007) and twelve Asian American female leaders' (Kawahara, Esnil, \& Hsu, 2007) achievement. Almost all of the women in Cubillie's and Brown's (2003) study identified their fathers as strong influences in shaping their thinking and enabling them to aspire to higher education and role achievement.

\section{Mentor support}

Mentor support plays a significant role for women taking leadership and management roles. By analysing secondary data in exploring the career paths of African American women presidents, Harris, et al. (2011) found that for African American women to achieve a presidency, mentoring was strongly recommended because mentors and networking may help women access significant information and opportunities for career advancement. In a New Zealand study, Airini, et al. (2011) identified what helps or hinders women to advance in university leadership roles. One of the facilitators was having senior leaders who support women to assume leadership roles. The importance of mentoring was also confirmed by 
Peters (2011) in the study of African American women achieving tenure in the field of educational leadership, and by Blackwood \& Brown-Welty (2011) research on women of color assuming leadership roles in California Community Colleges.

\section{Other factors}

Apart from personal factors, family support, and mentor support, some less common factors were also identified in the literature. For example, the importance of early educational and career success and teachers' inspiration was emphasized by the three 'first' Mexican American, Native American, and Asian Pacific/Asian American women presidents (Turner, 2007). Day-to-day application of organizational policies and practices could also help empower women (Airini, et al., 2011). By allowing women with full time appointments to work part time when necessary, universities provided some structural facilitators for female academics (Twombly, 1998). Female administrator's career advancement might also be facilitated by being able to move to another institution or by accepting an interim position (Blackwood \& Brown-Welty, 2011). Some female leaders' success resulted from adopting non-traditional leadership styles to bring diverse communities together (Turner, 2007).

Even though there have been some common themes with respect to facilitating female leadership in the academy, they are not necessarily universal. For example, although role models appeared to be essential to the success of academic American women of color (Blackwood \& Brown-Welty, 2011; Harris, et al., 2011; Peters, 2011), women in North America (Kelly, 2011) and New Zealand (Airini, et al., 2011), it was not obviously a factor for Costa Rican women academic leaders (Twombly, 1998) or Korean women (Johnsrud, 1995, cited in Twombly, 1998). Successful academic and administrative managers in New Zealand universities were proactive in building their career development plans (Airini, et al., 2011). However, female leaders of color in California Community Colleges did not have any well articulated career plans (Blackwood \& BrownWelty, 2011) and African American female community college presidents saw their career development just as "in the right place at the right time" (Gooch, 2009, p. 118, cited in Harris, et al., 2011). This may indicate the importance of socio-cultural context in determining what facilitates/hinders women's academic advancement. So it's important to widen our understanding in different contexts.

There is a gap in the literature in that most of the studies primarily focused on very senior women in more advanced countries such as the U.S. or New Zealand (Airini, et al., 2011; Kelly, 2011; Turner, 2007). When researchers examined the topic in less developed country contexts, they didn't distinguish academic from administrative leadership roles (Cubillo \& Brown, 2003) and when they did, the data was quite outdated (Twombly, 1998). In partly addressing this literature gap, this study furthers our understanding in how a particular group of middle-level academic managers (female Deans) from a developing country (Vietnam) have been hindered or facilitated in their career progress. The two major questions guiding this study are: 1) What are the barriers to female Deans taking Deanship positions at a Vietnamese university and 2) What are the facilitators for their pathways to the Deanship? 


\section{Context}

Empowering women in leadership and management has been a significant goal that Vietnam has aimed to achieve. Vietnam ranks second among Asia Pacific countries and 9th out of 135 countries worldwide in the number of female National Assembly Members. Even so, the percentage of female National Assembly Members for the 11th election is only 28\%. Apart from politics, Vietnamese women have taken leadership roles in fields such as economics, culture, social organizations, and educational institutions. Although, due to lack of data, no specific ratios could be identified, the numbers of women leaders are modest in comparison with males (Quy \& Nga, 2008).

In higher education, there have been no specific university policies on promoting women in leadership and management. Vietnamese universities generally conduct activities related to gender equity as stipulated by the Communist Party's leadership and the government's laws and policies. For example, each university generally has a Women's Association. Their major activity is to hold annual meetings for the university's female staff on Vietnamese Women's Day to praise women's achievements both at work and in raising and educating their children at home. These associations also organize sightseeing tours or holidays for women to socialize and network once or twice annually.

One of the two Vietnamese national universities was selected as the site for this research. At the time this research was conducted in 2009, the selected national university consisted of six university members ${ }^{3}$. Of their total 42 faculties only nine faculty Deans were female (21\%), coming from four of the six university members. On average, women represent $34 \%$ of the academic staff in these four university members. Female academics accounted for about $20 \%$ of the total academic staff with Doctoral qualifications. This figure is $15 \%$ at associate professor level, and well under 5\% at professor level. As stated in the University Regulations (Thủ tướng Chính phủ, 2010), it is necessary for both men and women to hold a Doctorate to be a Dean.

\section{Methods}

Face to face interviews were the primary method of investigation. All nine female Deans were invited to participate; however only six were able to participate in the research. One female Dean did not wish to participate; two others were on business overseas at the time the data was collected. One member of the Board of Rectors or one Human Resources Manager from each of the six universities was also invited to participate. However, only three male university leaders and two male Human Resources Managers were available to take part in the research. Because these participants were most likely to be decision makers on whether female academics were promoted, their perceptions helped to obtain a more comprehensive picture of the barriers to female Deans' career advancement.

\footnotetext{
${ }^{3}$ The two Vietnam National Universities are the two largest and most autonomous universities in Vietnam. Each national university consists of several independent mono-disciplinary university members.
} 
All participants were asked to share their perceptions of the status and empowerment of female Deans at their university, facilitators and barriers for women taking Deanship positions, and how they think their university and society can help women to overcome the obstacles in their career development. Six female Deans were also asked to describe times when incidents in work or nonwork situations have helped (or hindered) them developing as university managers. All interviews were recorded and transcribed in Vietnamese. Selected verbatim quotes were translated into English in the final report.

\section{Findings}

\section{The female Deans' Faculty profile}

The six female Deans have been in their current roles for between one and three years. Before their current position, they most commonly held an academic Head of Program or Deputy Dean Position. The average number of their Faculty's tenured staff is approximately 25, except for one Dean whose faculty has approximately 40 tenured lecturers. Each Dean is supported by one or two Deputy Deans. The number of students enrolled in each faculty varies from 300 to 1000 . One faculty provides doctoral training; all other faculties only deliver Master and Bachelor level courses. Females account for the majority of the staff and students in all of the six faculties. All of the female Deans have Doctoral Degrees; two have been promoted to 'Assistant Professor'. No female Dean is a 'Professor'.

\section{Barriers}

The most common barriers to women taking academic management positions as perceived by the respondents are strong family obligations, negative gender stereotypes, and women's unwillingness to take leadership roles.

\section{Strong family obligations}

According to the participants, strong family commitment is the biggest barrier to female Deans. This barrier is perceived by both university leaders as well as female Deans themselves. From a male university leader's perspective 'it seems to be the world's unwritten rule that women, not men must care about their family more' and therefore, 'women are afraid that if they take part in too many social activities and don't care much about their families, problems will arise'. This challenge is recognized by all of the female Deans. They say that the most common challenge for them is to fulfill their roles as a wife and a mother while working as a Dean:

'The workload is now becoming heavier and heavier so female academic leaders must know how to balance family life and university work'. (Female Dean)

'For me, the biggest obstacle is time constraints. Sometimes my husband complains about me spending inadequate time with my family and my children are sad because I am too busy'. (Female Dean) 
'My children are still small, so I have to take care of them. I didn't get the title 'excellent staff' in 2002 and 2003 because my child was often ill and I couldn't arrive at work on time. This is a very big challenge'. (Female Dean)

Having to take major responsibility for family, leadership and management work was perceived as 'not suitable' for women because 'leaders have to deal with a variety of social communications, go on business very often, and meet a lot of people' (Female Dean). So, if women are leaders 'sometimes they cannot come to their office on time' and 'their family duties affect university work' (University Manager). Therefore, male academics are valued more than females because 'males have more time for work than females' (University Manager). One university leader further commented that 'if we want women to participate more in social activities, the first task is to change society's assessment of women's work'.

\section{Stereotypes against women being leaders}

Stereotypes against females being leaders still exist and they do hinder female academics from becoming leaders and managers. Female academics are thought to be indecisive, less active, limited in thinking, and dare not take risks.

From the male university leaders' perspective, 'female managers are not very decisive' and 'women's disadvantage is their lack of organizational capability'. Some female Deans themselves also think that 'women are less active than men'. They blame this on women's characteristics:

'Women are very careful in making plans; however, they are less decisive and dare not take the risks. They care about too many things. Consequently, they may lose a lot of good opportunities'. (Female Dean)

'Sometimes I am not decisive enough so I cannot solve a problem completely. I also want to cover a lot of work. That is a disadvantage, not an advantage. Maybe it is due to my personality. (Female Dean)

or on women's general low level of education and experience compared to men:

'Women's thinking and management capabilities are more limited than those of men due to how they are educated, their living standards, and social circumstances. Except for females with very good living conditions or self-reliance, the majority of females' thinking is limited in terms of vision, depth, and width'. (Female Dean)

The issue that women do not support women was also identified:

'At our university, there are a lot of female academics so it is easy to choose a female leader; however, females don't seem to select other females, it is females' problem. I have a feeling that females don't vote for other females'. (Female Dean) 
Living in a culture where women's primary role expectation is as homemakers, some women are satisfied with doing a low ranking job and taking care of their family:

'In fact, many women hold an attitude that they shouldn't be too involved in social activities, their husband and children should be their primary concern. As the Head of a unit, they must deal with all problems and conflicts in their unit. This takes a lot of their time. Sometimes they just want to care about their family and look after their public appearance. They are fed up with all day management work'. (Female Dean)

This thinking appears to be common among Vietnamese women. However, in this study it is a viewpoint held only by a minority.

\section{The facilitators for female Deans' career advancement}

The major facilitators for female Deans' career advancement are self-effort, strong family support, and a favourable promotion context.

Female Deans' self effort:

The first factor that influences the female Deans' career advancement is their individual abilities and effort in gaining high level qualifications. All of the six Deans worked hard to complete their Doctoral training programs. They were among the first female Doctors in their specialization.

'I myself decided to study subject $X$. I didn't plan anything or didn't think that I would become a Dean one day. I myself felt that I had to study. The current position, first of all, is an outcome of my own motivation and efforts'. (Female Dean)

'The completion of my Doctoral thesis possibly made me a Dean. I am the first female PhD candidate who completed PhD study successfully'. (Female Dean)

'There must be a strong need for learning, an adequate level of expertise in the specialized area, and professionalism'. (Female Dean)

\section{Strong family support}

Apart from the Deans' personal ability and efforts, strong support from their families is a decisive factor. Support can come from the female Dean's husband, parents, and/or parents-in-law:

'I have an advantage because my husband is also a lecturer; he supports me to advance in my career. Sometimes, he is not happy when I come home late but generally, he is very supportive'. (Female Dean)

'My husband is very supportive because some relatives in my husband's extended family also work in my specialized area. My parents-in-law are 
also involved in a lot of social work and go on business extensively. Since I was married, my husband's family has created favourable conditions for me to study and participate in social activities. It has been a long supportive process. Now that my son follows my profession, my husband must also support me more'. (Female Dean).

'In fact, family support was the most important factor that helped me to become a Dean. I must say that I am very lucky because I have a Doctoral qualification while my husband doesn't. For Asians and the Vietnamese, it is not easy to accept a woman whose education is better than that of her husband. Luckily, my husband's parents are very understanding. They respect me because of my high-level education. My father-in-law used to be Deputy Director of the National Department of Agriculture, my motherin-law used to be a lecturer of English; therefore they supported me for my PhD study. Another advantage is that my family's financial situation is very strong'. (Female Dean)

The selection context

Organizational contexts play a very important role in deciding who can become Deans. In the cases of the female Deans, most of them were able to take management positions because no men were qualified or available. Four of the six Deans are Foundation Deans in their faculty.

'Actually, I was not elected or selected to be a Dean. I didn't apply for the post either. It came quite naturally. It seemed inevitable. When I started working in this Faculty, there was only one male colleague who had graduated from Russia. He was the one who offered me my position in the Faculty. However, he only worked in the Faculty for two years, and then had to stop for military duties. There was only me left in the faculty at that time [with a Doctoral qualification]. So I am not selected or appointed. It just came naturally'. (Female Dean)

'In fact, there was nothing special about my career advancement. Our specialized subject group was founded in 1995 consisting of only me and another female PhD. When there was a need to nominate a Head of the group, people could only select between me and the other female. I was chosen because I was younger. After that, in 2001, the group became a Faculty and I was nominated Dean. Also, there were not many people who had a Doctoral qualification at that time'. (Female Dean)

'I worked as Deputy Dean from 2005 - 2007. When I started the role I had nearly finish my PhD. In 2008, when the former Dean retired and my department was separated into an independent Faculty, I became Dean. I was strongly qualified for the post since I had a Doctoral qualification and was a Communist Party member. Apart from that, in terms of capabilities, no one else in the faculty was qualified. If I wasn't qualified, no one from the Faculty was better than me at that time'. (Female Dean)

In general, there are some common features in the six Deans' career advancement. None of them had any clear plans for their career development (similar findings can be found in Blackwood \& Brown-Welty, 2011); however, they all had 
excellent learning capabilities and demonstrated great effort and determination to progress. In addition, they had very strong family support, especially from their husbands and parents-in-law in studying further. Thanks to these favourable factors, they became outstanding in their faculties. Having almost no competitors for the position at the time of selection, they became the strongest candidates for the Deanship. Similar findings of being in the right place at the right time are also found in Gooch (2009) and Ausmer (2009), cited in Harris, et al., (2011).

\section{Discussion}

A number of barriers and facilitators for women taking Deanship positions in this study confirm findings from previous research on this subject. In terms of the challenges, female Deans in the current study face almost all the common barriers identified in the literature. Psychologically, prejudicial attitudes against female managers are quite common among both male university managers and female Deans. Women were perceived as having some personal attributes that are inappropriate for being leaders, for example, being indecisive, narrow thinkers, and not being risk takers. Similar findings can be found in the literature (Eagly \& Carli, 2007; Heilman, 2001; Schein, 2001). However, the think manager-think male attitude was not clearly expressed.

Women's strong family obligations act as the strongest macro socio-political cultural barrier to female academic advancement. This 'unwritten rule' places a heavy burden on female Deans', both physically and mentally. The psychological effects of this social imperative can be seen as one type of 'glass ceiling' for academic women (Cotter, Hermnsen, Ovadia, \& Vanneman, 2001; Powell \& Graves, 2003, cited in Harris, et al., 2011). This is because university leaders are often in favor of men in selecting a manager since as a social norm men have more time for work than women. Psychologically, women themselves may feel ashamed if they are involved too much in career activities and cannot devote adequate time to their family and consequently face family problems. While this finding resonates very well with previous research of Neale (2010), Luke (2000), and Olser (1997, cited in Oplatka, 2006), the study does not seem to support the Asian values of feminine propriety as a barrier for women advancement as found in a study by Luke (2000). This is an important observation, and may be due to Vietnam's particular history.

Surprisingly, even though universities did not seem to have any available gender profile data or any particular policies on supporting women, respondents appeared to be happy with the current level of university support. No participants claimed university structures and policies as a barrier to female academic advancement. One female Dean even thought that 'the university is right in not having any special support for women' because 'if anyone can satisfy the criteria, s/he can become a manager'. Although this finding is not exclusive to the current study similar findings can be found in a study on Turkish universities by White \& Ozkanli (2011), it differs greatly from most other studies in 'Western' contexts in which organizational structures, norms, and values are perceived as barriers to women's career advancement (Airini, et al., 2011; Doherty \& Manfredi, 2006; Tilbrook, 1998; White, 2003.). Perhaps, the female Deans themselves have internalized a sense of gender neutrality at work as a result of the deeply rooted social expectation of their family roles. This finding may indicate that Vietnamese 
academic women's slow professional progress is mainly due to the social expectations of their role in the family. Organizational interventions may help, but they may not be the decisive factors in removing barriers for academic women, if the broader social barriers are not removed. Possibly, women should learn to take the advantages of the work-family interface rather than considering work-family balance as a major concern (Cheung \& Halpern, 2010).

Despite barriers, the women in this study are successful in their career. Women's self-ability and determination appear to be the prerequisites for success. Not surprisingly, family support is the strongest facilitator for the female Deans not only prior to but also during their Deanship. In addition, the way in which they were selected for the role appears to be the final decisive factor. These findings support previous research on the facilitators of female academics' advancement: personal factors (Blackwood \& Brown-Welty, 2011; Cubillo \& Brown, 2003; Twombly, 1998), family support (Cheung \& Halpern, 2010; Kawahara, et al., 2007; Turner, 2007) and a favorable selection context (Gooch, 2009, pp 118, cited in Harris, et al., 2011). However, unlike in some other studies (Airini, et al., 2011; Blackwood \& Brown-Welty, 2011; Harris, et al., 2011; Peters, 2011), in this study the success of the female Deans wasn't facilitated by mentors.

This study is limited to one university and its findings cannot be generalized to all female Deans in Vietnam. But in this case study, apart from their own ability and efforts, female Deans depend on 'luck' as a factor for their career advancement. They seemed to be lucky because at work they were simply in the right place at the right time. There is nothing wrong with someone being lucky in life in general, in one's career advancement in particular; but it can be argued that in order for women to advance more systematically, there is much more to be done than for women sitting passively in one place and waiting for their luck to come. The female Deans in this study have very powerful family support because their family members understand the need to empower them. This may suggest that in order for women to be empowered and promoted, we need to enhance people's awareness of freeing and empowering women's potential. Possibly, in order to make this change, women themselves need to first change their thinking (Mann, 1995).

This study adds to the literature on barriers to and facilitators for female academic advancement in higher education. It helps to illuminate the experiences of academic women taking management positions from a research context in a developing South East Asian country. Such specific knowledge is very important in building gender equity programs in these contexts.

Although this research has achieved its overall aim of exploring the barriers to and facilitators of female academic Deans' advancement at a national university in Vietnam, there are nonetheless limitations to this research work. The study is based on a quite small sample of female Deans and university leaders at only one institution in Vietnam. The results cannot represent the whole of Vietnamese higher education, much less that of all or even only South East Asian developing countries. However, as there is a lack of research on this subject in Vietnam, it is important to have this exploratory study in the Vietnamese context. It is expected that additional research will be undertaken to provide a broader understanding of the advancement of female academic leaders in higher education in Vietnam and other developing countries. Future research is planned in other Vietnamese 
universities, involving a greater number of stakeholders from wider university contexts. It would be interesting to compare the facilitators of and the barriers to female Deans in Vietnam with those in other Asian contexts such as China, Thailand, Malaysia, etc. The similarities and differences in female academic Deans' facilitators and barriers from such comparative studies would help universities learn how to better empower and promote female academic leaders.

\section{Conclusion}

In conclusion, this is an exploratory study on barriers to and facilitators of female Deans' career advancement at a Vietnamese university. An important limitation of this study is that it is based on only one university and there is a need to extend the study to a number of other universities before any reliable generalisations can be drawn. However, in the absence of such research in the Vietnamese context, the study helps to narrow the knowledge gap by providing perceptions of male university leaders and female Deans on the factors that enhance or hinder female academic leadership and management. The conclusion that can be drawn from this study is that family support is a very important factor that can significantly impede or facilitate female academic career progress in Vietnam. In addition, women themselves can be both an object and an agent of change in empowering female leadership.

Since having more women as leaders and managers can promote not only gender equity but also organizational productivity and human capital development, appropriate measures should be taken to empower female leaders. In the Vietnamese context, as the social expectations of women as dutiful wives and mothers are so strong, appropriate policies and measures must be developed to lessen the time demands of women's domestic work and childcare so that women can invest time as much as men do in their career progress. At the same time, women should learn to take the advantages of the work-family interface rather than considering work-family balance as a major concern (Cheung \& Halpern, 2010). Additionally, female academics must be aware of and interested in their career advancement. Without female academics' personal interest in and commitment to their own careers, it is difficult to see how any of the other measures designed to promote their career advancement will prove fruitful. Vietnamese higher education is presently undergoing a radical transformation in the attempt to create a modern higher education system for the nation. Women leaders and managers have a crucial role to play in this process.

\section{References}

Airini, Collings, S., Conner, L., McPherson, K., Midson, B., \& Wilson, C. (2011). Learning to Be Leaders in Higher Education: What Helps or Hinders Women's Advancement as Leaders in Universities. Educational Management Administration \& Leadership, 39(1), 44-62.

Bailyn, L. (2003). Academic careers and gender equity: Lessons learned from MIT. Gender, Work and Organization. Gender, Work, and Organization, 10(2), 137-153.

Bell, S. (2009). Women in Science in Australia: maximizing productivity, diversity, and innovation: FASTS.

Blackwood, J., \& Brown-Welty, S. (2011). Chapter 6: Mentoring and interim positions: pathways to leadership for women of color. In G. Jean-Marie \& 
B. Lloyd-Jones (Eds.), Women of color in higher education: changing directions and new perspectives (Vol. 10, pp. 109-133). Bingley, U.K.: Emerald Group Publishing Limited.

Bornstein, R. (2008). Chapter 7: Women and the college presidency. In J. GlazerRaymo (Ed.), Unfinished agendas : new and continuing gender challenges in higher education (pp. 162-184). Baltimore :: Johns Hopkins University Press.

Chen, E. W.-C., \& Hune, S. (2011). Chapter 8: Asian American Pacific Islander women from $\mathrm{Ph}$. D. to campus president : gains and leaks in the pipeline. In G. Jean-Marie \& B. Lloyd-Jones (Eds.), Women of color in higher education: changing directions and new perspectives (Vol. 10, pp. 163190). Bingley, U.K.: Emerald Group Publishing Limited.

Cheung, F. M., \& Halpern, D. F. (2010). Women at the top: Powerful leaders define success as work + family in a culture of gender. American Psychologist, 65(3), 182-193.

Cubillo, L., \& Brown, M. (2003). Women into educational leadership and management: international differences? Journal of Educational Administration, 41(3), 278 - 291.

Doherty, L., \& Manfredi, S. (2006). Women's progression to senior positions in English universities. Employee Relations, 28(6), 553-572.

Eagly, A. H., \& Carli, L. (2007). Women and the labyrinth of leadership. Harvard Business Review, September, 63-71.

Eagly, A. H., \& Johannesen-Schmidt, M. C. (2001). The Leadership Styles of Women and Men. Journal of Social Issues, 57(4), 781-797.

Harris, S. L., Wright, S. J., \& Msengi, C. (2011). Chapter 4: African American females' career paths to the presidency : navigating the glass ceiling challenge. In G. Jean-Marie \& B. Lloyd-Jones (Eds.), Women of color in higher education: turbulent past, promising future (Vol. 9, pp. 79-98). Bingley, U.K.: Emerald Group Publishing Limited.

Heilman, M. E. (2001). Description and prescription: How gender stereotypes prevent women's ascent up the organizational ladder. Journal of social issues, 57(4), 657-674.

Kawahara, D. M., Esnil, E. M., \& Hsu, J. (2007). Chapter 14: Asian American women leaders : the intersection of race, gender, and leadership. In J. L. Chin, B. Lott, J. K. Rice \& J. Sanchez-Hucles (Eds.), Women and leadership: transforming visions and diverse voices (pp. 297-313). Malden, MA: Blackwell Pub.

Kelly, M. L. (2011). Next in line: Women chief academic officers, their experiences and career aspirations. University of Pennsylvania.

Luke, C. (2000). One step up, two down: women in higher education management in South East Asia. In M. Tight (Ed.), Academic Work and Life: What it is to be an Academic, and How this is Changing (Vol. 1, pp. 285-305). Greenwich, Conn. ;London: JAI.

Mabokela, R. O. (2003). "Donkeys of the University": Organizational culture and its impact on South African women administrators. Higher Education, 46(2), 129-145. 
Madsen, S. R. (2010). Chinese Women Administrators in Higher Education: Developing Leadership throughout Life Academic Leadership. The online Journal, 8(2).

Mai, T. T. B. (2007). Phu nu va su tham gia vao cong tac quan ly nha truong dai hoc o Vietnam. Nghien cuu gia dinh va gioi, 17(3), 25-35.

Mann, S. (1995). Politics and power in organizations: why women lose out. Leadership \& Organization Development, 16(2), 9-15.

McNeill, D. (2007). Few Women Reach the Top in Japan's Universities. Chronicle of Higher Education(54), 47-47.

Meek, V. L., Goedegebuure, L., Santiago, R., \& Carvalho, T. (Eds.). (2010). The Changing Dynamics of Higher Education Middle Management (Vol. 33). Dordrecht: Springer.

Meyerson, D. F., J. (2000). A modest manifesto for shattering the glass ceiling. Harvard Business Review, Jan/Feb, 127-136.

Neale, J., \& Ozkanli, O. (2010). Organisational barriers for women in senior management: a comparison of Turkish and New Zealand universities. Gender and education, 22(5), 547-563.

Oplatka, I. (2006). Women in educational administration within developing countries: Towards a new international research agenda. Journal of Educational Administration, 44(6), 604-624.

Peters, A. L. (2011). Chapter 7: Black women faculty in educational leadership : unpacking their silence in research. In G. Jean-Marie \& B. Lloyd-Jones (Eds.), Women of color in higher education: turbulent past, promising future (Vol. 9, pp. 147-167). Bingley, U.K.: Emerald Group Publishing Limited.

Quy, L. T., \& Nga, N. T. T. (2008). The Vietnamese women in management and leadership. Tap chi cong san (Journal of Communism), 20(164).

Schein, V. E. (1973). The relationship between sex role stereotypes and requisite management characteristics. Journal of Applied Psychology, 57(2), 95100.

Schein, V. E. (2001). A global look at psychological barriers to women's progress in management. Journal of social issues, 57(4), 675-688.

Tharenou, P. (1994). Commentary: why so few female academics? Australian Journal of Management, 19(2), 221-228.

Thủ tướng Chính phủ. (2010). Quyết định số 58/2010/QĐ-TTg, 22/9/2010, Điều lệ trưòng đại hoc (Decision number 58/2010/QĐ-TTg, 22/9/2010, University Regulations).

Tilbrook, K. E. (1998). An exploration of the current under-representation of senior women managers in Australian universities. Women in Management Review, 13(8), 291-298.

Turner, C. S. V. (2007). Pathways to the presidency: Biographical sketches of women of color firsts. Harvard Educational Review, 77(1), 1-38.

Twombly, S. B. (1998). Women academic leaders in a Latin American university: Reconciling the paradoxes of professional lives. Higher Education, 35(4), 367-397. 
Va'zquez-Cupeiro, S., \& Elston, M. A. (2006). Gender and academic career trajectories in Spain: From gendered passion to consecration in a Sistema Endoga'mico? Employee Relations, 28(6), 588-603.

Valian, V. (1998). Women in Academia Why so slow?: The advancement of women. Cambridge: M.I.T. Press.

White, K. (2003.). Women and Leadership in Higher Education in Australia. Tertiary Education and Management, 9, 45-60.

White, K., \& Ozkanli, O. (2011). A comparative study of perceptions of gender and leadership in Australian and Turkish universities. Journal of higher education policy and management, 33(1), 3-16.

Winchester, H., Lorenzo, S., Browning, L., \& Chesterman, C. (2006). Academic women's promotions in Australian universities. Employee Relations, 28(6), 505-522.

\section{Acknowledgement}

This study was funded by the Cambridge - Viet Nam Women Leadership Programme. The author acknowledges the very thoughtful comments and advice on earlier drafts from Professor Vincent Lynn Meek, Professor Sharon Bell and the two anonymous reviewers. 


\section{University Library}

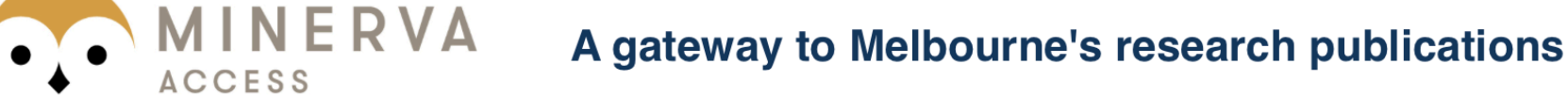

Minerva Access is the Institutional Repository of The University of Melbourne

Author/s:

Nguyen, TLH

Title:

Barriers to and facilitators of female Deans' career advancement in higher education: an exploratory study in Vietnam

Date:

2013-07

Citation:

Nguyen, T. L. H. (2013). Barriers to and facilitators of female Deans' career advancement in higher education: an exploratory study in Vietnam. Higher Education, 66 (1), pp.123-138. https://doi.org/10.1007/s10734-012-9594-4.

Persistent Link:

http://hdl.handle.net/11343/283244 